\title{
On the Staining Capacity of the Nucleolus and its Physiological Significance.
}

\author{
By
}

Kunio Sato.

Department of Anatomy, Okayama Medical college.

(Director: Prof. K. Kōsaka.)

With 7 text figures.

Contents.

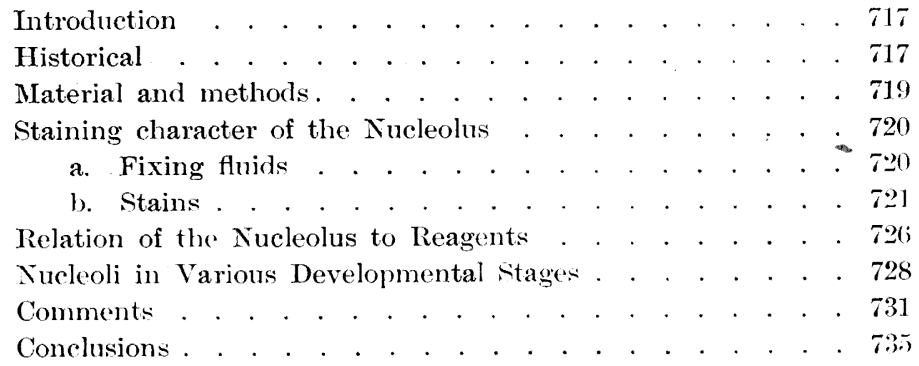

\section{Introduction.}

Since the discovery of the nucleolus in nucleus by Fontana (1781), a host of investigators have striven to find its physiological significance and the origin of its peculiar stainability. To our regret, however, we have not as yet arrived at an acceptable conclusion ; some take it for a metabolic product with little significance to cell functions, while others think that it is a most important reservoir or pre-substance of chromatin, being stained partly acidophilously and partly basophilously. Still others consider it nothing other than a crystalloid.

At the Institute of Anatomy Prof. Kōsaka suggested me to attack the nucleolus problem from its staining capacity, and in the following pages I shall describe some of my results.

\section{Historical.}

Carnoy and Lebrun (1s97-1899), Nussbaum (1913), Lubosch 
(1914), Wagner (1923) et al. found double stainability of the nucleolus (germinal spot) and maintain that the nucleolus is acidophilic but its peripheral portion may be basophilic, although this condition varies a great deal according to the different kinds and physiologic phases of cells.

What was said of the egg cells is also confirmed in the somatic cells. Macklin (1916) found that the nucleolus of connective tissue cell very finely stained by haematoxylin and gentian violet. Chlopin (1925) called attention to the fact, that the nucleolus in emigrated fibroblasts consisted of two different substances as to its stainability; in the eosin azur preparation the main substance of the nucleolus is metachromatically stained. Levi (1896), Marinesco (1905) and Havet (1905) recognized in the nerve colls that the core of nucleolus was acidophilous, while the peripheral part was basophilous; in the spinal ganglion cells Smirnow (1902) obtained the same results. Mühlmann and Lache (1911) state that in the nerve cells nucleinic substance is present either diffusely in the nucleolus or attached on its surface as small particles. Concerning the staining capacity the above mentioned fact is also confirmed by Murct (1895) and Saguchi (1920) in gland cells, by Maziarski (1910) in intestinal cells, by Hertwig (189s) in Actinospherium and by Wassilief (1907) in the spermatoblasts.

From these facts we can draw up the following conclusion. The nucleolus is not throughly acidophilous in its proper character, but it possesses in it more or less basophilous chromatin, which is found more in the periphery and less toward the center; the volume of the nucleolus changes according to physiologic condition of the nucleus.

Is to the physiological significance of the nucleolus it has been discussed for a long time without arriving at a definitive conclusion; diametrically stand two leading opinions, one admitting and the other minimizing its importance for cell life.

One of the leaders of the latter was Haecker (1893-1895). He and his students investigated the nucleoli of the egg-cells in several invertebrates and reached the following conclusion. "Generally we conceive that the nucleolus has no chromatin in it, nor has it any organization at all. Though it has been taken for granted that it performs reserve or nutritive functions when chromatic substance in nucleus is abundant or deficient, I do not think it is a right explanation. Moreover it is a product of notabolism which was formed in or near chromatic element during the vegetative cell activity, whereas it ranishes from nuclear space at the beginning of mitosis." "It is by no means. conceivable," he adderl, "nucleolus is a typical reserve material for the 
formation of chromosomes or other structures of mitotic flgure. It varies so great that it is hard to give any definition even." In addition to Haecker's opinion, Heidenhain (1907) mentioned as follows, "the quantity of the nucleolar substance depends upon the degree of the metabolism in the nucleus or in the cell ; the greater metabolic activity the more the nucleolar substance." In short he recognized that there existed an intimate relation between the quantity of nucleolar substance and that of chromatin.

The other hypothesis is that the nucleolus plays an important part for activity of both the nucleus and cell. So Flcmming states that the nucleolus is always present in all kinds of cells, forming an important constituent of nucleus and exhibiting fairly constant reaction. The same opinion is held by many other investigators: so also by Carnoy and Lebrun (1897), Fick (1899), Lubosch (1903), Rhode (1903), Vejdowsky (1911-1912) and others. According to Carnoy and Lebrun, both chromatin and nucleolus are not at all different substances, but they only represent different phases of the same substance. Fick conceives of the nucleolus as a nuclein reservoir or perhaps as a nuclein factory. Lubosch and Rhode assert that the nucleolus at least has a genetic connection with nuclein corpuscles which form a net-work in the nucleus, and indeed the former can be dissolyed in the latter, from which it again newly formed. Moreover Tejlowsky says that chromosome is the center of nucleolus.

Besides there are many other views: Korschelt (1899) thinks the nucleolus as an accumulation of a substance in the nucleus and sometimes in the cytoplasin. According to Nontgomery (1899) the nucleolus. probably has a direct relation to the nutritive process, while Jourgensen (1913) insists on the utmost importance of the nuclcolar sulistance for cell life.

From the above mentioned statements it may be said that there is a certain genetic relation between nucleolar substance and chromatin.

\section{Material and Methods.}

To account for double stainability of the nucleolus we can think of the following posibilities: 1 . it may be due to the difference in chenical nature of the two constituents of nucleolus; 2. it is caused by the difference of physical nature, though chemically the same; 3 . though the two parts are the same in their physical as well as chemical nature, the difference is produced by either fixing or staining fluids.

Fresh egg-cells of the swan-mussel, Cristaria plicata, were put 
on the slide and various reagents were added on them in order to examine them in toto under the microscope. For permanent preparations almost all fixing fluids and stains now in use were tried with various combinations and durations. In order to see the seasonal changes the eggs were studied from the ealiest deposition to its end, at the intervals of ten days. The ovary of Cristaria plicata can easily be separated from other organs; for it is situated at a bending of the intestine in the foot immediately beneath the liver.

\section{Staining Characters of the Nucleolus.}

\section{a. Fixing fluids.}

In order to see the relation of fixing fluids and the double stainability of the nucleolus, the ovary was treated with various fixing and staining fluids, and I found that after the fixation with almost all reagents I employed except cupper sulphate and potassium bichromate, the nucleolus showed its double stainability. And in fact the stronger the dehydrating power, the better the double stainability is manifested, as is shown in the following table.

Table I:

\begin{tabular}{|c|c|c|c|}
\hline Fixing fluids & $\begin{array}{c}\text { Grade of } \\
\text { double } \\
\text { stainability }\end{array}$ & Fixing fluids & $\begin{array}{c}\text { Grarle of } \\
\text { double } \\
\text { stainability }\end{array}$ \\
\hline absolute alcohol & H & areton & $\mathrm{HH}$ \\
\hline $90 \%$ alcohol & $H$ & trichlor-acetic acid & $H$ \\
\hline $80 \%$ alcohol & H & picric acid & + \\
\hline sulfosalicylic acid-aleohol & H & chromic acid & \pm \\
\hline alcohol-acetic acid & H & potassium bichromate & - \\
\hline Carnoy's solution & $H$ & Müller's solution & + \\
\hline metlyyl alcohol & H & formalin & \pm \\
\hline sublimate & + & Orth's solution & \pm \\
\hline 'Zenker's solution & $H$ & Schaffer's solution & \pm \\
\hline cupper sulphate & 一 & osmic acid & \pm \\
\hline sublimate + $\mathrm{Nacl}$ & + & Flemming's fluid & + \\
\hline boiling & + & nitric acid & + \\
\hline $\begin{array}{l}\text { - no double sta } \\
+ \text { weak ," } \\
\text { H medium , } \\
\text { H strong , }\end{array}$ & $\begin{array}{l}\text { abilitỵ } \\
, \\
, \\
\text { ", }\end{array}$ & , & \\
\hline
\end{tabular}


On the Staining Capacity of the Nucleolus and its Physiological Significance. 7:

b. Stains.

I made following experiments with rarious stains taking into account time factor, velocities of diffusion and adsorption, and chemical actions.

1. Single Stains.

Whatever stains are used I found always a small deeper stained part and a larger lighter stained part in the nucleolus and generally speaking double stainability appears remarkably in the eggs of medium size i.e., at the middle stage of growth period. The boundary between the two different stained parts is not sharp; in most cases the deeper stained part is projected from the spherical nucleolus, but sometimes it is situated at the center of the latter. In either case the nuance gradually fades from the center of the intensively stained part towards the periphery. Besides there exists an important time factor in staining, as will be discussed later on.

Table II.

\begin{tabular}{|c|c|c|c|}
\hline Stains & $\begin{array}{l}\text { Grade of } \\
\text { double } \\
\text { stainability }\end{array}$ & Stains & $\begin{array}{c}\text { Grade of } \\
\text { double } \\
\text { stainability }\end{array}$ \\
\hline $\operatorname{eosin}$ & H & haematoxylin & 册 \\
\hline acid fuchsin & H & safranin & $H$ \\
\hline janus green & $H$ & methyl green & $H$ \\
\hline aniline blue & H & thionin & $\mathrm{HH}$ \\
\hline picric acid & $H$ & fuchsin & $H$ \\
\hline light green & $H$ & methylene blue & $H$ \\
\hline methylene green & 世 & toluidin blue & 册 \\
\hline orange yellow & + & trypan blue & $\mathrm{HH}$ \\
\hline
\end{tabular}

2. Double Stains.

I tried several double or multiple stains and arrived at the following results: If the section is stained by an acid or a basic dye successively (irrespective of their order) or by a mixture of both dyes, the result is not constant regarding the double stainability. It may be mentioned that there are three variables: a) physical difference of plasmosome and karyosome, b) difference in the power of diffusion of stains and c) time factor i.e., duration of staining. 
As an example I shall describe the results obtained by the methyl green-eosin method. The section of eggs are stained with $1 \%$ aqueous solution of methyl green for 5 minutes and then with eosin for so many minutes. Both the plasmosome and karyosome are stained violet-red,

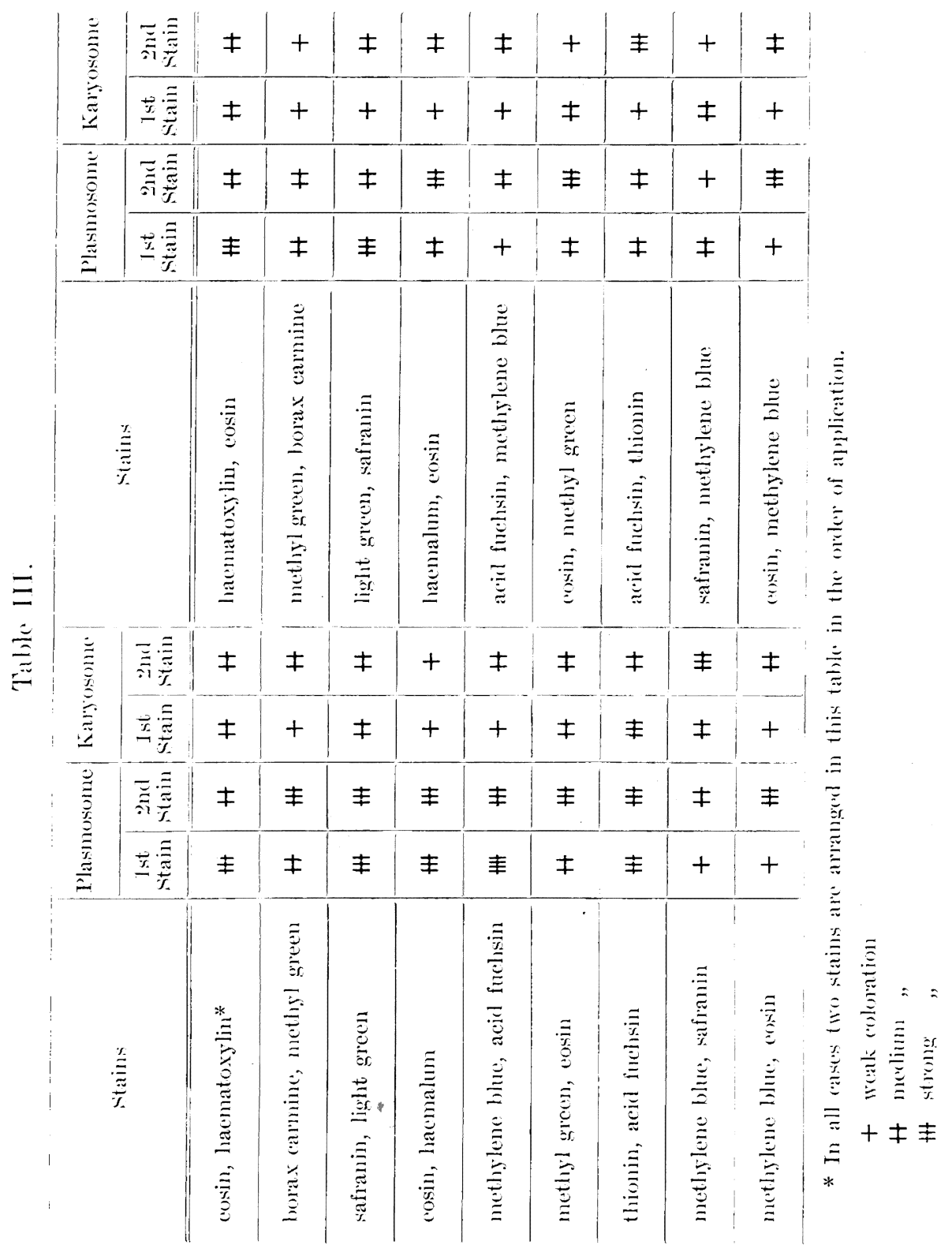


On the Staining Capacity of the Nucleolus and its Physiological Significance. 72:

but the former is deeper than the latter; the plasmosome takes more eosin than methyl green, while the karyosome stains equally by both dye-stuffs, so that the boundary of the two parts is relatively sharp; if the order is reversed, that is, first by eosin and then by methyl green, both the plasmosome and karyosome takes a violet-cobalt color, but the former shows more of the color of methyl green, while the latter that of eosin more.

But this does not take place in all cases of double staining as is seen from the following table. The results are rather variable, the plasmosome not always being acidophil and the karyosome not always basophil. Neither does the nuance depend exclusively upon the order of stains used. All the aniline stains were used as $1 \%$ aqueous solution except eosin which was $3 / 10 \%$. Concerning staining time, washing, clearing etc. care was taken to keep them as much uniform as possible for all cases.

As is seen from the above table the density of a tissue, and the diffusive power of a dye-stuff have more important meanings regarding double stainability than the reaction of dye-stuff. So I undertook the following experiments.

To $1 \%$ aqueous solution of aniline blue was added $1 \%$ solution of acid fuchsin in equal proportion and sections were stained with this mixture. Both are acid stains, but they have different diffusive powers. After 3 minutes both plasmosome and karyosome became violet, having taken both the dyes lightly, but the former was stained deeper by acid fuchsin which has greater diffusive power, while the latter was stained more by aniline blue which has smaller diffusive power. After 6 minutes both components of nucleoli were stained deeper by aniline blue than before, although plasmosome has a deeper color tone of acid fuchsin than karyosome. After 9 minutes' staining, both are more strongly stained by aniline blue, the tone of acid fuchsin being scarcely visible in plasmosome and not at all in karyosome.

This shows clearly that when stained with a mixture of two stains the nucleolus first takes chiefly the more diffusive dye and later that of smaller diffusive power becomes predominant, the former color gradually decreasing, although plasmosome holds a deeper tone of this color than karyosome for a long time. The following table shows that the above mentioned fact holds good not only of the mixture of two acid dyes, but it is also true in the case of two basic dyes mixture and even in that of an acid and a basic dye.

In most cases plasmosome is stained deeper than karyosome, but 


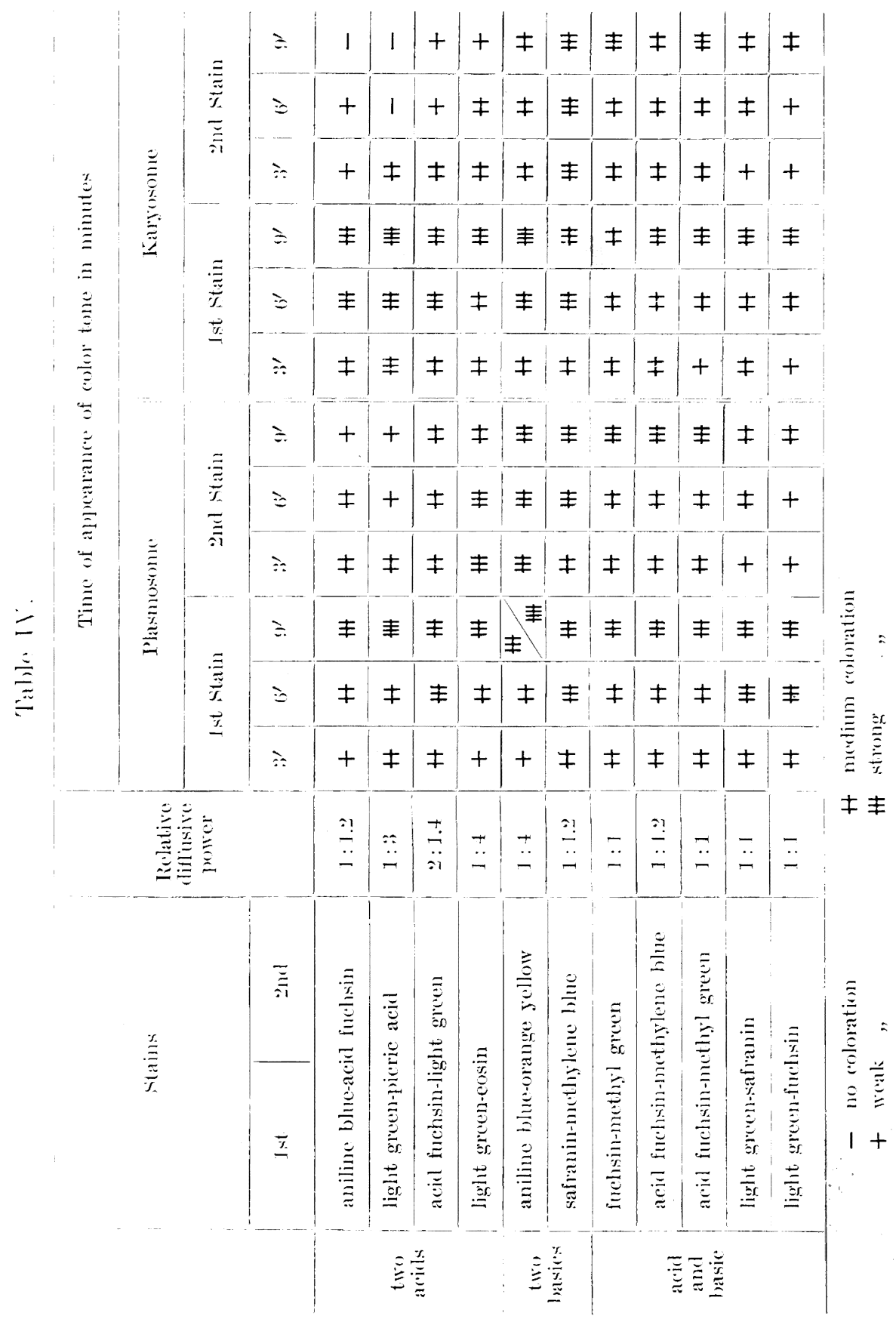


On the Staining (apratity of the Nucleolus and it: Physiological Significance. 7.5

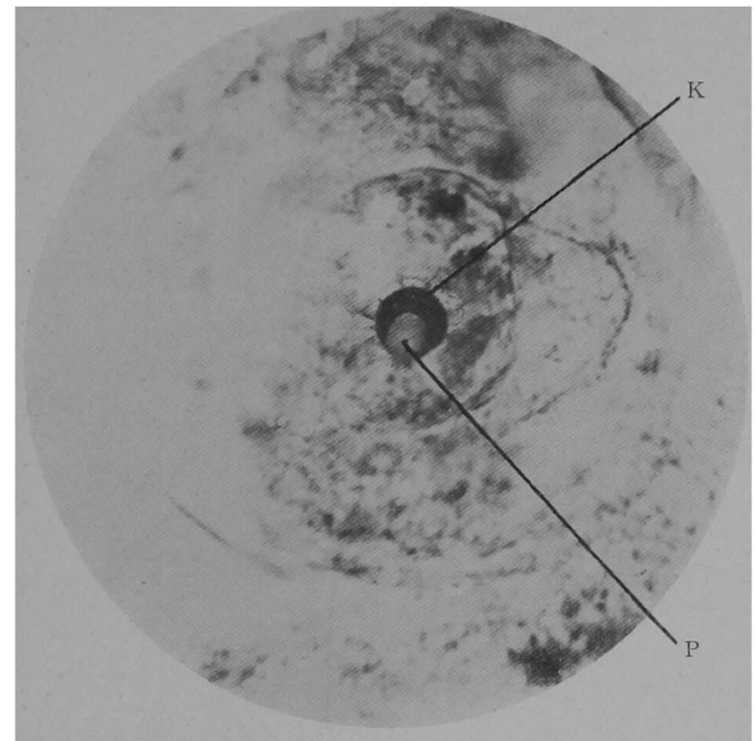

Fig. 1.

Nucleolus of ego-eell of swan-mussel. 30 seconcls' staining. Ilasmosome is lighter than karyosome. Ieeitz objective 1/12 inm., ocular 4, camera length $17 \mathrm{~cm}$. sometimes the matter is reversed as is the case with 3 minutes' staining of light ereen-picric acid, safraniinmethyl blur etc. It is certain that this is due to nothing but the diffusive power of the dye, dmsity on the tissue, and time factor as I thall sprak later on.

In orcler to ascertain what rôle time factor plays rewalding the double stainability of nucleolus, I trierl to stain sections with single dyes in various staining time from 5 seconds to 5 minutes.

Both the plasmosome

and karyosome stained alike and faintly, after is seconcls in Böhmer's haematoxylin, c.g. After 15-30 seconds some plasmosomes wore stained a little lighter than karyosome (Fig. 1). When the section was stainerl for 3 minutes, some plasmosomes, strange to say, were darker than karyosomes. After 5 minutes' staining, the nucleoli stained too decp) to sor double stainability, but if decolorized for several scemels with acid alcohol, double stainability appeared very clearly, plasmosome assuming a

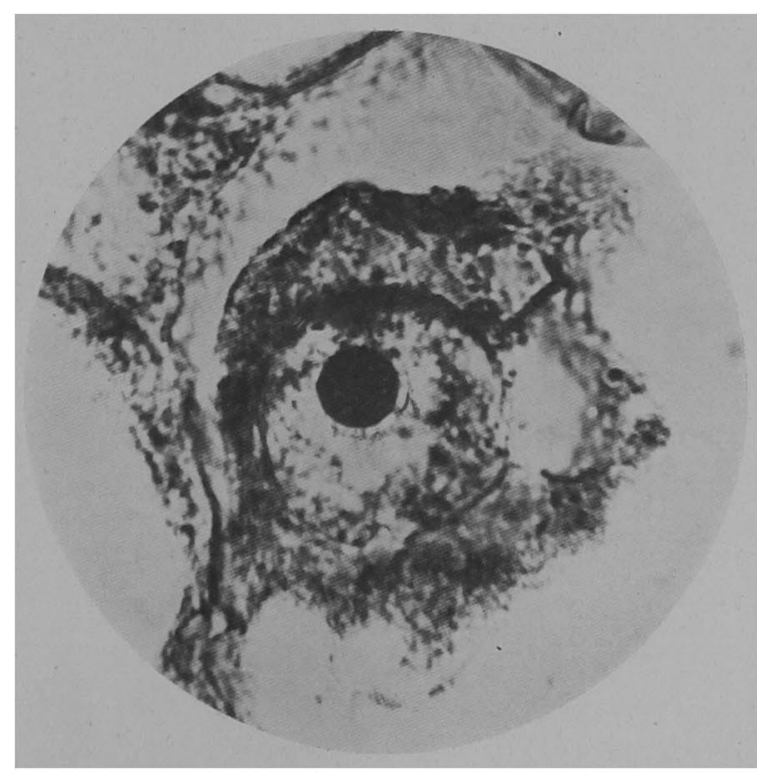

Fig. 2.

i) minutes' staing. Both plasnoseme and karyoseme stain alike. Same magnification as figure 1 


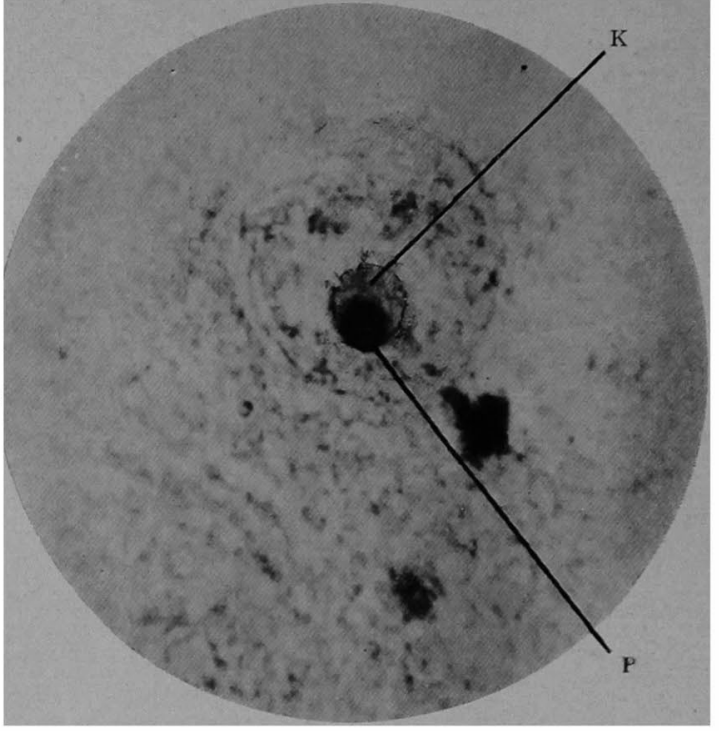

Fig. 3.

5 minutes' staing, followed by decolorization for 30 seconds with acid alcohol. Plasmosome stains deeply and karyosome faintly. Same nagnification as figures 1 and $:$. deep blue-black color, and karyosome taking a faint blue (Fig. 3).

In short Böhmer's haematoxylin stains nucleoli deeper in proportion to the staining time, and that first karyosome deeper, but later plasmosome deeper.

This reversal of stain, however, did not occur always in other stains. For example, fuchsin sometimes stains plasmosome darker than karyosome from the beginning (5 seconds' staining), and I think this is due to the fact that fuchsin has a greater diffusive power than haematoxylin. In the case of eosin stain-

ing the double stainability cannot be found until 30 seconds, though the dyc-stuff has a greater diffusive power than either haematoxylin or fuchsin, and the reason to account for this may be that the greater the diffusive power is, the sooner the decolorization takes place.

It any rate the above mentioned fact gives support to the physical theory of staining, that is, the diffusive power of dye-stuffs and the density of structure play the most prominent rôle. The detailed description and criticism will be deferred (p. 731 et seq.).

\section{Relation of the Nucleolus to Reagents.}

In order to ascertain chemical nature of the two components of nucleolus and chromatin I took out the ripe eggs of swan-mussel from the orary and directly applied various reagents on them.

$$
\text { a Alkalies. }
$$

If some drops of $1 \% \mathrm{KOH}$ or $\mathrm{NaOH}$ are poured on the egg cell, the nucleolus swells, a little distending the nuclear membrane. After 30 seconds the membrane bursts, then the intranuclear substance swells gradually in consequence of direct contact with the reagent. Plasmosome 


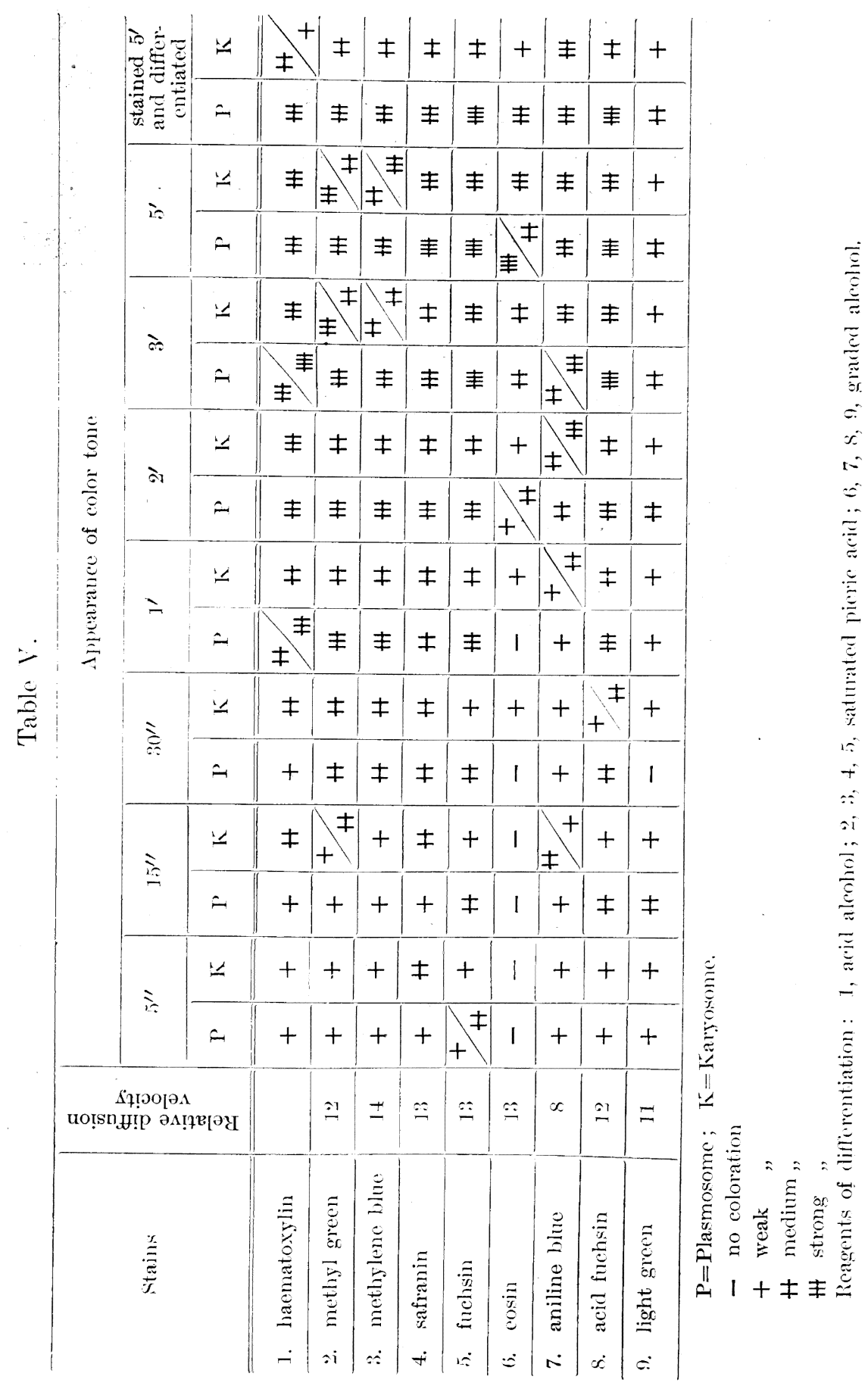


was still dark though to less degree than before, while karyosome and chromatin becomes transparent and reflects light very strongly. The grade of swelling is plasmosome $<$ karyosome $<$ chromatin. If so treated egg-cell is subjected to the action of $3 \%$ solution of the same reagent, the nucleolus shrinks a little for a while, but then it continues swelling. If, however, directly $3 \%$ solution is applied no initial shrinkage is seen. $5 \%$ solution of $\mathrm{KOH}$ or $\mathrm{NaOH}$ has the same effect on the eggs, but finally chromatin dissolves and disappears, and after some minutes karyosome is dissolved, while plasmosome remained intact. $10 \%$ solution dissolves plasmosome in several minutes.

Magnesium sulphate, potassium phosphate and lime water all show the same effect within the range of from $5 \%$ to $20 \%$.

\section{b Acids.}

If $0.5 \%$ solution of acetic acid is added to egg-cell, the nuclear membrane bursts after 2 minutes and chromatin coagulates to small, glossy granules, and the nucleolus somewhat swells and becomes paler. The same thing happens with $1 \%$ and $3 \%$ solutions, but quicker than with $0.5 \%$ solution. In $5 \%$ solution both karyosome and chromatin become soft swollen mass, which erentually breaks up into numerous fine granules contrary to the case with alkaline solutions. If we use $10 \%$ or a stronger solution of acetic acid, chromatin, accessory nucleolus and karyosome swell up and disappear, while plasmosome resists longer, becoming swollen and brighter, but finally it also vanishes. If water is added to the preparation after a woak solution of acetic acid chromatin, accessory nucleolus and karyosome which have been swollen disappear but plasmosome shrinks somewhat. If a salt solution is used instead of water both plasmosome and karyosome shrink accorling to the percentage of salt solution.

By using hydrochloric acid and formic acid within the range of from $0.5 \%$ to $10 \%$ the same phenomenon is observed.

Now in conclusion it may be stated : 1) Strong solutions of alkalies and acids generally cause the swelling of intranuclear substance. Alkaline solutions dissolve it, while acids coagulate it. 2) The nucleolus, especially plasmosome, shows the most remarkable resistance to both acids and alkalies. 3) Chromatin and karyosome show almost the same reaction to both acids and alkalies.

\section{Nucleolus in Various Developmental Stages.}

I have followed the changes of nucleolus in the eger at rarious developmental stages. 
a carly stage.

At the beginning of April and the end of August the eggs of swanmussel begin to grow. At this time the nucleus is reratively large for the cell, but the nucleolus is still small and lies in the center of the nucleus or a little eccentric. It does not show double stainability. In most cells, around each nucleolus there is a clear ring shaped or crescent shaped area. ${ }^{1)}$ From the nucleolus or from the clear area sereral slender threads radiate toward chromatin granules. They stain leep with haema-

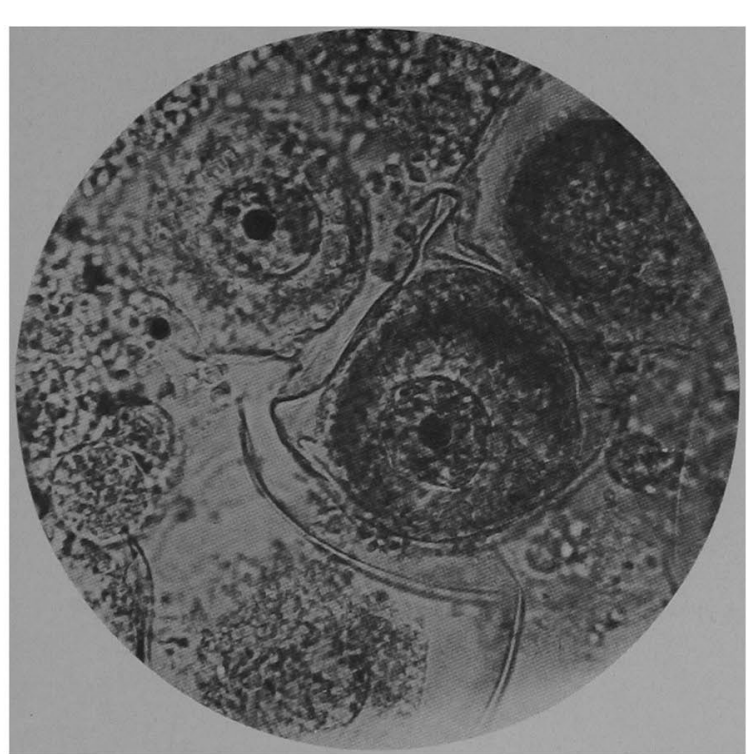

Fig. 4.

Egg-cell of swan-mussel, at the early stage of its derclopment. The nucleolus is small and dense, without showing any different stainability; the nucleus is rich in chromatin. Leitz objective 1/12 imm., ocular t, camera length $17 \mathrm{~cm}$. toxylin, and may be regarded as "processes" of Hertwig, Maziarsky and others. So the surface of the nucleolus is not smooth but rough as it were a chest. nut-burr. Chromatin is rich in the nucleus at this stage, forming a net-work with many threads and granules which are generally fine near the nucleolus but grow coarser towards the nuclear menbrane (Fig. 4).

b Intermediate Stage.

In May and October the nucleolus of the aggs is larger as compared with that of the stage just mentioned and we can find most clearly its double stainability, as is shown in decolorized haematoxylin preparations. The position is the same as it was in the previous stage. In most cases the small decper stained plasmosome projects a little from the general surface of lighter stained karyosome. Though the shape of the clear area and the slender threads are the same as in the early stage, there is a great reduction of chromatin, so that only a small quantity

1) This clear area is an artifact due to fixation as we cannot see it in the living egg. 
of chromatin is attached to the nuclear membrane, the whole nucleus looking very clear (Fig 5).

\section{c Full grown Egg.}

The eggs become full grown at the end of June and Norember, the nucleoli often increasing in number. The double stainability can only be

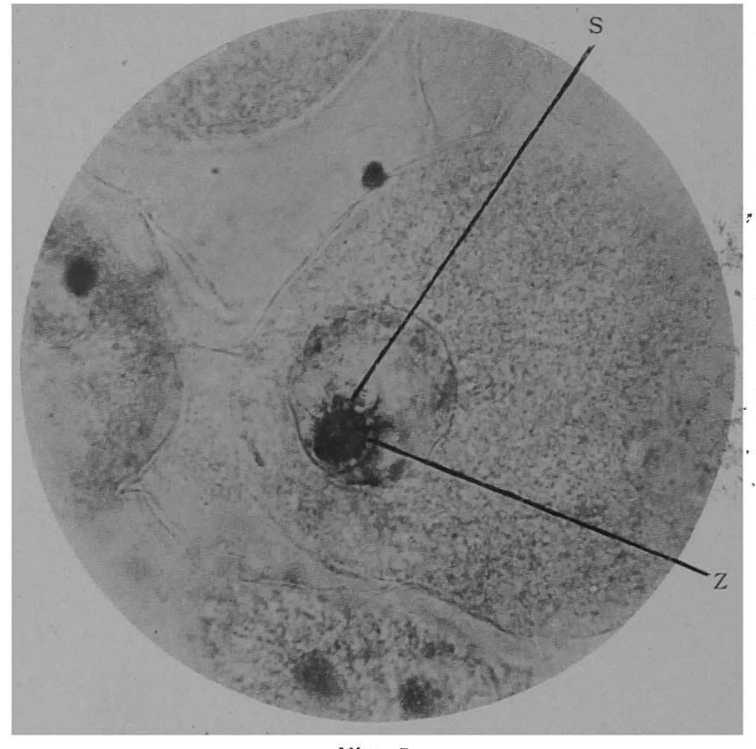

Fig. .).

Eug at an intermediate stage, the double stainability is seen; the slender threalis ( $S$ ) rarliate through the clear-zone $(Z)$ and connect with chromatin corpuscles, which are still scanty. Same magnification as figure 4 . obtained by a long staining and a prolonged decolorization. In most cases plasmosome projects over karyosome. Plasmosome has decreaserl while karyosome has increased in size. The surface of the nucleolus is somewhit granulated and rarely we find racuoles in it. The elear area is found as before, but slender threads are scarcely visible. The most noticeable feature of this stage is the appearance of so-called accessory nucleoli and the increase of chromatin contents of the nucleus. The accessory nuclcoli are variable in size and number and are situated directly on the nuclear membrane or on the principal nucleolus, their shape being spherical or reticular. The stainability of the accessory nucleolus is almost the same as that of karyosome and chromatin net-work (Fig. (i).

\section{d Degenerating eggs.}

It the beginning of July and the end of November the ovary of swan-mussel contains no eggs, for they have been discharged already. The ovary is filled with numerous granules which stain deep with haematoxylin and many exfoliated epithelial cells. In the ovary of swan-mussel kept in the laboratory from $\Lambda$ pril to the end of July we find degenerating eggs. Both the cell-body and nucleus have decreased in size and no accessory nucleoli are present. In the principal nucleolus 


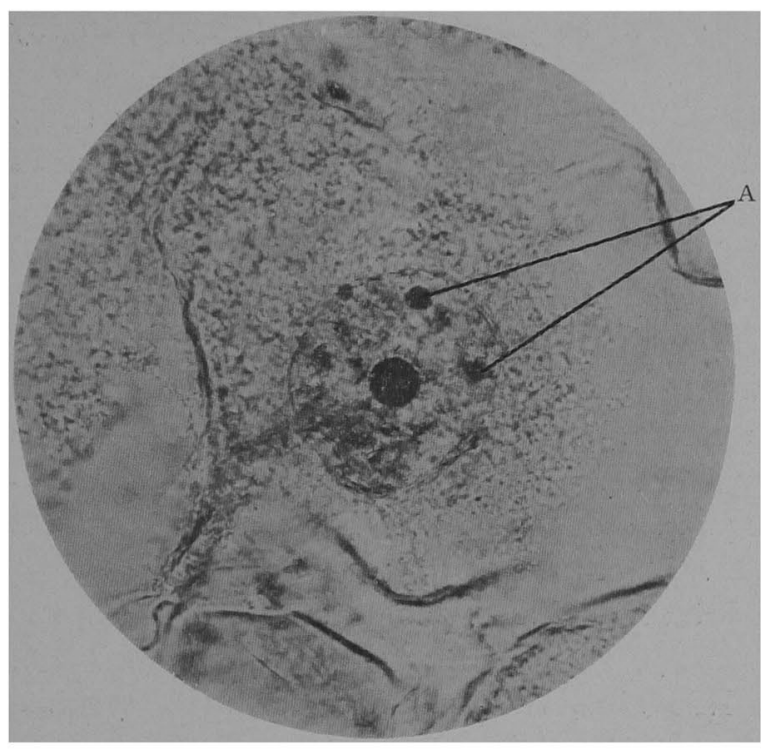

Fig. 6.

Full grown egr. Accessory nucleoli (A) are seen ; the nucleus has acquired much chromatin. Same nagnification as figures 4 and 5 . double stainability is very clear. Plasmosome is almost as large as karyosome, thus the whole nucleolus assuming the shape of an hour-glass. Vacuoles are formed in plasmosome. Chromatin is so deficient that we see it only as finest corpuscles here and there, and constituting only a meager net-work which attaches to the nuclear membrane. Concerning the clear area and the slender threads there is nothing particular to say (Fig. 7).

Now I have reached the following conclusion :

1) The eggs of the swanmussel begin to grow at the begimning of April in the ovary and are laid by the end of July. Then in some cases another lot of eggs begins to grow at the end of August and is laid at the end of November. 2) Between nucleolus and chromatin there is a genetic relation and a material exchange which goes on as the eggs grow.

\section{Comments.}

\section{A. Staining Reactions:}

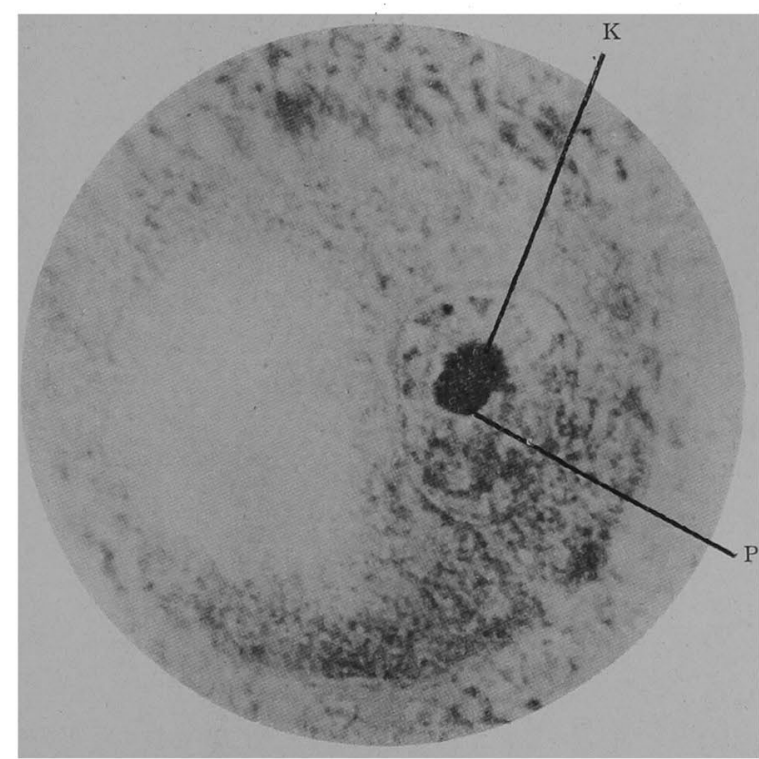

Fig. 7.

Fgg at a degenerative stage. The nucleolus is largo: the double stainability is clearly seen and no aceesiory nucleoli are wesent. Same magnification as other figures. upon some of leading 
theories of staining in as much as they have direct bearing upon my present theme.

First chemical theory of staining will be considered. This is based on the assumption that different stainability is duc to different chemical substance as Unna maintains. But this is untenable for the case of double stainability, since it does not explain why plasmosome which is considered acidophilous stain always deeper not only with acid-dyes but also with basic-dyes than karyosome which is regarded as basophilous.

There is another chemical theory of staining that the substance which is to be stained has certain power to split the dyes. But this cannot $b x^{2}$ adopted as an explanation of double stainability of the nucleolus, since it is difficult to explain the fact that plasmosome always stains deeper than karyosome whatever stain one may use.

It should be mentioned that double stainability of nucleolus has nothing to do with metachromasy, since with stains like gentian violet, toluiclin blue, neutral red, Nile blue, both plasmosome and karyosome show only a difference in shade but not in color itself.

Next we come to physical theory of staining. Cierke, Fischer, Pappenheim, Möllendorff and others are of the opinion, that diffusion has a decided meaning to the result of staining. And staining is the function of both the size of dye-stuff particles and the density of the substance to be stained. By this theory double stainability of nucleolus can be explained without difficulty.

1) The fact that plasmosome takes always a decuer color than karyosome, no matter what dyes are used, is due to the difference of density of the two, that is, plasmosome holds particles of dye-stuff better than karyosome (Table II).

2) Generally speaking it does not make any difference in what order two stains are used as to double stainability of the nucleolus. Plasmosome prefers to take acid dyes because they are more diffusible than others (Table III).

3) When the nucleolus is stained with a mixture of two acid or basic dyes of different diffusive powers, plasmosone is always stained first by the dye of greater diffusibility. The reason is self-evident. After that, howerer, plasmosome is infiltrated by the slower diffusible dye which is not easily driven out afterward, if it has once entered the substance to be stained. For instance, the relative diffusive power of aniline blue and orange yellow is $1: 4$. When the mixture of $1 \%$ aqueous solutions of both dyes is used for nucleolar staining, plasmosome is yellow, karyosome is green after 3 minutes, after 6 minutes plasino- 
On the Staining Capacity of the Nucleolus and it Physiologieal Significance. 7:3:;

some is green and karyosome blue with a slight tint of yellow, after 9 minutes plasmosome takes blue with a yellow tint and karyosome a decp blue, and finally after a longer staining the whole nucleolus takes a deep blue colour of aniline blue. If a nucleolus is stained by a mixture of an acid and a basic dye plasmosome is always stained by the one of greater diffusibility irrespective of its chemical nature. It is impossible to understand those facts on the basis of the chemical theory ('Table IV').

4) The time relation of staining seems to give a strong support to physical theory. Haematoxylin, for instance, stains karyosome deeper than plasmosome in 3 minutes (Fig. 1). After 3-5 minutes no double stainability is visible (Fig. 2), or rather plasmosome is stained a little deeper than karyosome. If the staining time surpasses 5 minutes, the whole nucleolus is stained too dark to distinguish the two parts, but after decolorization with acid alcohol for some minutes karyosome becomes light, while plasmosome remains in a dark color (Fig. 3). The explanation will be as follows: In 3 minutes haernatoxylin cammot infiltrates into the dense plasmosome, though it penetrates into the loose karyosome; after a longer staining haematoxylin enters both plasmosome and karyosome. But in decolorizing karyosome loses the color, because it is less dense and the dye-stuff easily goes out, while plasmosome retains the color longer on account of its greater density. Without decolorization with acid alcohol plasmosome is stained sometimes deeper than karyosome, this is due to the partial decolorizing effect of subsequent treatments such as washing, dehydration, clearing etc. Noreover those dye-stuffs like picric acid, eosin, orange yellow etc., which have greater diffusive power stain plasmosome always deeper than karyosome even in the case of 3 minutes' staining; the reason, I think, is too clear to be mentioned here (Table V).

5) Fixing fluids like alcohol, aceton, Carnoy's solution enhance difference in density between plasmosome and karyosome and consequently the double stainability of nucleolus, on the contrary, formalin which has a swelling effect makes the difference of the density rather indistinct. Potassium bichromate which strongly impairs the structures of nucleolus and nucleus, loes not cause any difference in density at all. In both cases, therefore, we do not get double stainabtlity.

I must here take up Witt's dissolution theory. According to this staining is accomplished by the dissolution of dye-stuff into the substance to be stained. But this does not seem to explain double stainability.

Now coming to the theory of electric adsorption. When we immerse a solid body which is negatively charged in an acid stain, the artorptive 
power of the dye-stuff will be very weak, on the contrary, if it is immersed into a basic stain it will take more molecules of dye-stuff. This theory does not fit well with the fact concerning the staining of nucleolus. If this theory be true, one and the same nucleolus should be at one time electrically negative and at another positive according to the nature of stains. Moreover plasmosome should always have a greater electric charge than karyosome. But it is impossible to believe.

After comparing various theories concerning the staining, I do not hesitate to accept the physical theory for the explanation of double stainability of the nucleolus, especially that which lays stress on the diffusive power of the dye-stuff on the one hand and on the density of the structure to be stained on the other, although I would not dismiss entirely the idea of chemical affinity. In my opinion it is quite absurd to call plasmosome acidophil and karyosome basophil.

B. Physiological significance of Plasmosomes and Karyosomes.

As to the physiological significance of the nucleolus, I believe it is an important cell structure, a reservoir of chromatin as Flemming Korschelt, Vejdowsky et al. insist on.

In the egg of swan-mussel of an early stage, one cannot see double stainability (Fig. 4). Later the differentiation of plasmosome and karyosome takes place, karyosome lies by plasmosome in the shape of a ring or a crescent (Fig. 5). Karyosome becomes larger than plasmosome; finally the latter becomes very small (Fig. 6). I think plasmosome, karyosome, accessory nucleoli and the chromatin net-work or corpuscles have little chemical difference, but they differ from each other in density. In ny opinion plasmosome is the densest part in the nucleus and it gives off karyosome; the latter affords chromatin which is the loosest among them. As to the formation of the accessory nucleoli $I$ think that they are formed either from the principal nucleolus or from chromatin net-work. Here I emplasize again that nucleolus is the reservoir of chromatin, and it supplies to other structures in the cell, if need be.

In degenerating eggs plasmosome appears again in karyosome close to its edge or in its center. In this case the nucleus is poor in chromatin and contains no accossory nucleoli (Fig. 7 ), and it seems to me that the principal and accessory nucleolus are again formed from chromatin.

In my observation plasmosome resists most strongly to any acid or alkaline solution, next to it karyosome and accessory nucleolus, while chromatin is most liable to be affected by them. This fact seems to afford another proof that plasmosome is denser than others. 
On the Staining Capacity of the Nucleolus and it: Plysiological Nignificance. Tin

\section{Conclusions.}

From the study of the eggs of Cristaria plicata, a freshwater. bivalve I have come to the following conclusions:

1) The nucleolus is an important cell-organ as a reservoir of chromatin. In some cases (in degenerating cells, for instance), it is formed from chromatin.

2) The nucleolus is composed of two parts, a deep stained (plasmosome) and a light stained (karyosome) part. This difference is shown with any stains.

3) Plasmosome is the densor part, from which comes karyosome, and then the loosest chromatin, and vice versa. Their chemical nature is almost the same.

1) The accessory nucleoli which appear in the full-grown eggs come generally from karyosomo and are stained alike but sometimes from plasmosome and rarely from chromatin.

5) Plasmosome resist the action of acid or alkaline solutions most strongly, karyosome and accessory nucleoli are next to it, while chromatin is most sensitive to these chemical.

6) So-called acidophile part (plasmosome) is always stained deeper than the so-called basophile part (karyosome) by any dye-stuff no matter if it is acid or basic. When the eggs are stained by a mixture of two dyes the so-called acidophile part is stained by the one of more diffusibility. The degree of the infiltration of the dye-stuff varies according to the time of staining. The terms "acidophile" and "basophile" do not seem to be adequate, instead I would suggest non-committal terms "deep staining" and "light staining".

7) The double nature of nucleolus can best be brought about by alcohol, aceton, Carnoy's or Zenker's solution, but formalin, Schaffer's. Orth's solution, chromates and boiling seem to demolish it.

\section{Literature Cited.}

Auerbach, L., Zur Kenntnis der tierischen Zellen. SB. d. k. Press. Akad. d. Wiss. Berl., 1890.

Becher, S., Untersuchungen über Echtfärbung der Zellkerne. Berl., 1921.

Berg, F., Arch. f. mikr. Anat., Bd. 62, 1903.

Bito, F., Über die Wirkung der Fixierungsmittel. Okayama Igakkai Zasshi, Xr. 44:;, 1926. 
Boveri, T., Zell-studien. Jena, 1905.

- Ergebnisse ïber die Konstitution der chromatische Substanz des Zellkernes Jena, 1904.

Blum, F., Enzyklopädie der mikr. Technik. 1910 и. 1926

Chlopin, N. G., Studien über Gewebskulturen im artfremden Blutplasma. Zeitschr. f. mikr. Anat. Forwch., Bd. 2, 1925.

('owdry, F., General cytology. New York, 1924.

- Special eytology. New York, 1928.

Fischer, 1., Fixicrung, Färbung u. Bau des Protoplasmas. 1899.

Fischer, M., Ölema and Nephritis. New York, 1915.

Flemming, W., Irch. f. mikr. Inat. Bd. 4\%, 1893.

-_ Zellsubstanz, Kern und Zellteilung. I‘:ipzig, 188*.

Georgievics, G., Handbuch der Farbenchemic. Icipzig, 1!2-4.

Haecker, V., Das Keimbläschen, seine Elemente und Lageveränderumgen. Ir.h. f. mikr. Anat., Bd. 42, 1893.

-, Die Vorstadien der Eireifung. Arch. f. mikr. Inat., Bd. 45, 189.5.

II a mburger, H., Osmotischer Druck und Ionenlehre. 1924.

II avet, J., L'origine des nucleolés vrais on plasmosomes des cellules nerveuses. Inat. Anz., Bd. 29. 1906.

Ileidenhain, M., Beiträge zur Topographie und Histologie der Kloake und ihre drüsigen Jrinexa bei den einheimischen Tritonen. Arch. f. Zellf., Bd. 10, 1913.

Hertwig, O., Allgemeine Biologie. 191"

Höber, Physiologische Chemie der Zelle и. d. Gewebe. 1:2:t.

Kosaka, K., On the staining method. Nisshin Igakkai Zasshi, 1926.

Kraus, Handbuch der Zoologie. 1!:0.

I.ache, I. G., L'aspet du noyau de la cellule nerveusi dans la métlude à l'àrgent reduit. Inat. Inz., Bd. $24,1906$.

Lewis, M. R., Mitochondria (and other cytoplasmic structures) in tissue cultures. Amer. Journ. of Anat. vol. 45, 1895.

II atsunra, Y., On the staining factor of acid-fuchsin. Okayama Igakkai Zasshi, Xr. 447,1926 .

Möllendorff, Die Dispersität der Farbstoffe ete. Anat. Hefte, Bd. 5:3, 1915.

Yussbaum, J., Zur Kenntnis der Verhaltens des Kernkörperchens und dessen Derivate bei der Orogenese einiger Tiefseeknochenfische. Anat. Anz., Bd. 43, $191: 3$.

Pappenheim, 1., Grundriss der Farbenchemie zum Gebrauch bei mikr. Arbeiten, 14. 1901.

Saguchi, S., Studies on the glandular cells of the frog's pancreas. Amer. Journ. of Inat., Vol. 26, 1920.

- Zytologischen Studien. Heft. I, 19:7.

Sannomiya, N., Experimentelle Studien über die sog. sauren Kerne sowie äber ihre histologische Natur. Okayama Igakkai Zasshi, Nr. 44, 19ㄹ․

Tollyosniczky, Enzyklop,äjie d. mikr. Techinik, 1926.

Unna, P. (i., Zur Konntnis der Kerne. Monatshefte f. prakt. Dermatol., Bd. 41, 191.).

Wagner, K., Über die Entwicklung des Froscheies. Arch. f. Zellf., Bal. 17, 1923. 